\title{
COMPARISON OF THE FORCE DETERIORATION OF DIFFERENT ORTHODONTIC ELASTOMERIC MATERIALS IN ARTIFICIAL SALIVA: AN IN VITRO STUDY

\author{
Rajkiran Lokhande ${ }^{1}$, Tushar Patil ${ }^{2}$, Avinash Mahamuni $^{3}$, Krishnakumar Jaju $^{4}$, Ketan Gore ${ }^{1}$, Rajlaxmi Rai ${ }^{1}$ \\ ${ }^{1}$ Sr. Lecturer, ${ }^{2}$ Professor \& HOD, ${ }^{3}$ Professor, ${ }^{4}$ Reader, Dept. of Orthodontics, \\ YCMM \& RDF's Dental College, Ahmednagar, Maharashtra.
}

\begin{abstract}
The orthodontist must be able to choose an elastic band with force-extension characteristics that are most suitable for the particular tooth movement required. From a clinician view it would be mandatory not only to know the clinical aspect of these elastics but also their basic properties, in order to extract the most out of these polymers. Stretching of elastics are thought to be the primary cause of force degradation of orthodontic elastics but there is evidence of increased force degradation of elastics when exposed to various types of substances like artificial saliva, phosphoric acid and citric acid. Orthodontic elastics have received mixed reactions of practitioners as reported by the vendors of orthodontic supplies. The present study is designed to compare the force deterioration of different orthodontic elastomeric materials in artificial saliva medium. There was a force deterioration over time in all materials, being greatest on the seventh day of the experiment, especially more in the chains; From the third to the fourth week there was no noticeable force degradation in either group; By the end of the experiment, modules showed less deterioration of the force compared to the chains and threads.
\end{abstract}

Keywords: Elastomeric chains; Elastomeric threads; Elastomeric modules.

\section{INTRODUCTION}

Elastics and Elastomers are routinely used as an active component of orthodontic therapy. Elastics have been a valuable adjunct of any orthodontic treatment for many years. There use, combined with good patient cooperation, provides the clinician with the ability to correct both Antero-posterior and vertical discrepancies. Elastomer is a general term that encompasses materials that, after substantial deformation, rapidly returns to their original dimensions.

The orthodontist must be able to choose an elastic band with force-extension characteristics that are most suitable for the particular tooth movement required. Force decay characteristics and force relaxation patterns of elastomeric materials are influenced by various factors such as manufacturing techniques, environmental conditions and chemical composition as well as morphology and dimensions of the elastomers.

From a clinicians point of view it would be mandatory not only to know the clinical aspect of these elastics but also their basic properties, in order to extract the most out of these polymers. Light continuous forces provides rapid tooth movement with least patient discomfort and minimal tooth mobility during orthodontic treatment [1]. Chain elastics are one of the active components of orthodontics which provides such type of forces and augments the arch-wire forces. Orthodontic elastics

DOI: $10.31878 /$ ijcbr.2018.51.11
eISSN: $2395-0471$
iSSN: $2521-0394$

used in mouth, along with the application of force have a disadvantage that they undergo force degradation as soon as first day of use [2].

Numerous studies have been carried out to investigate the effects of $\mathrm{pH}$ and temperature on force degradation and showed a significant decrease in force of elastics. Stretching of elastics are thought to be the primary cause of force degradation of orthodontic elastics $[3,4]$ but there is evidence of increased force degradation of elastics when exposed to various types of substances like artificial saliva [5], phosphoric acid and citric acid [6]. Orthodontic elastics have received mixed reactions of practitioners as reported by the vendors of orthodontic supplies.

The present study is designed to compare the force deterioration of different orthodontic elastomeric materials in artificial salivary medium.

Aims \& Objectives: To analyze and compare the force deterioration of different orthodontic elastomeric materials such as elastomeric chain, elastomeric thread and modules in artificial saliva.

\section{MATERIALS AND METHODS}

Place of research: This in-vitro study was carried out in the Department of Orthodontics and Dentofacial Orthopedics, YCMM \& RDF's Dental College, Ahmednagar.

Inclusion criteria: This study includes different orthodontic elastomeric materials like elastomeric chains, elastomeric threads and modules. As the composition of the above mentioned materials was same, we opted for Ortho Organizers, USA.

Correspondence: Dr. Rajkiran Lokhande, Sr. Lecturer, Dept. of Orthodontics YCMM \& RDF's Dental College, Ahmednagar, Maharashtra. Email: lokhande.rajkiran@gmail.com

(C) Authors; 2019. International Journal of Clinical and Biomedical Research, Sumathi Publications.

This is an Open Access article which permits unrestricted non-commercial use, provided the original work is properly cited.

(CC BY-NC-SA 4.0) 
Sample size: 150 pieces of elastomers from the company (Ortho Organizers, USA) was studied.

Table 1. Composition of artificial saliva*

\begin{tabular}{l|l}
\hline Component & $\begin{array}{l}\text { Quantity } \\
\text { Grams/L }\end{array}$ \\
\hline Methyl-p-hydroxybenzoate & 2 \\
\hline Sodium carboxymethyl cellulose & 10 \\
\hline $\mathrm{KCl}$ & 0.625 \\
\hline $\mathrm{MgCl}_{2} \cdot 6 \mathrm{H}_{2} \mathrm{O}$ & 0.059 \\
\hline $\mathrm{CaCl}_{2} \cdot 2 \mathrm{H}_{2} \mathrm{O}$ & 0.166 \\
\hline $\mathrm{K}_{2} \mathrm{HPO}_{4}$ & 0.804 \\
\hline $\mathrm{KH}_{2} \mathrm{PO}_{4}$ & 0.326 \\
\hline
\end{tabular}

${ }^{*} \mathrm{pH}$ of artificial saliva was adjusted to 6.75 with $\mathrm{KOH}$.

The testing of these materials was in various intervals of time i.e. $1^{\text {st }}$ day, $7^{\text {th }}$ day, $14^{\text {th }}$ day, $21^{\text {st }}$ day, $28^{\text {th }}$ day. 12 acrylic plates, each of size $25 \mathrm{~cm}$ x $6 \mathrm{~cm}$ were made. In which 4 plates were for elastomeric chains, 4 were for elastomeric thread, and 4 were for modules. Each acrylic plate consisted of 10 pairs of nails which kept the elastomers stretched. The stretch of these elastomers was around double its length i.e. 100\% extension [7], the holes were drilled accordingly in the acrylic plates. The initial length for elastomeric chains was $15 \mathrm{~mm}$, the initial length for elastomeric thread was $20 \mathrm{~mm}$, and the initial length of the modules was $2 \mathrm{~mm}$. So, the holes were drilled around $30 \mathrm{~mm}$ distance for elastomeric chains, $40 \mathrm{~mm}$ distance for elastomeric thread, and 4 $\mathrm{mm}$ distance for the modules. The elastomers to be tested were stretched over the appropriate steps and left for different time intervals up to 4 weeks. All the elastomers were kept stretched on the nails which were mounted on the acrylic plates at the appropriate distance. In order to simulate oral condition, the specimens were stored in an incubator at body temperature $\left(37 \pm 1{ }^{0} \mathrm{C}\right)$ immersed in artificial saliva. The specimens were divided into five categories and were tested at $1^{\text {st }}$ day, $7^{\text {th }}$ day, $14^{\text {th }}$ day, $21^{\text {st }}$ day, $28^{\text {th }}$ day. Mechanical tests were performed by means of force gauge which is a portable electronic scale. The force measured in this experiment was in grams.

Principle of the force gauge: It consists of a locking system where in the elastomeric thread is kept at a distance of $40 \mathrm{~mm}$, elastomeric chain at $30 \mathrm{~mm}$ and modules at $4 \mathrm{~mm}$. As there is a spring incorporated between the pulley and the acrylic plate it negates the undue pressure and undue frictional forces on the elastomers.

Statistical analysis: Two way analysis of variance ANOVA was used to analyze the difference among mean force decay in the three materials and time interval (days) and materials. One way analysis of variance (ANOVA) was used to compare the difference among mean force decay with the material. Statistically significant value taken was $(\mathrm{p}<0.05)$.

\section{RESULTS}

Force measurements for each of the fifty samples of the three test materials i.e. chains, threads, and modules were obtained at specified intervals during the 28-day test period. These measurements were used to determine the force deterioration of each test material. The control group was taken as $1^{\text {st }}$ day and the intervals of the force measurement i.e. $7^{\text {th }}, 14^{\text {th }}, 21^{\text {st }}, 28^{\text {th }}$ day were compared to the control group. For the standard group the force measurement were done at $0,5 \mathrm{mins}, 10 \mathrm{mins}$ and then after the mean value was taken. The same procedure was done for each of the three materials and then the statistical analysis was done.

In the first descriptive statistics the comparison of force deterioration was done with the days or the time interval. It suggested that on $7^{\text {th }}$ day there was $55.48 \%$ of the force decay, on the $14^{\text {th }}$ day there was $56.92 \%$ of force decay, on $21^{\text {st }}$ day there was force decay of $67.54 \%$ and on the $28^{\text {th }}$ day there was force decay of $71.59 \%$. This measurement showed that initially there was higher decay of force which gradually slowed down but increased at $28^{\text {th }}$ day.

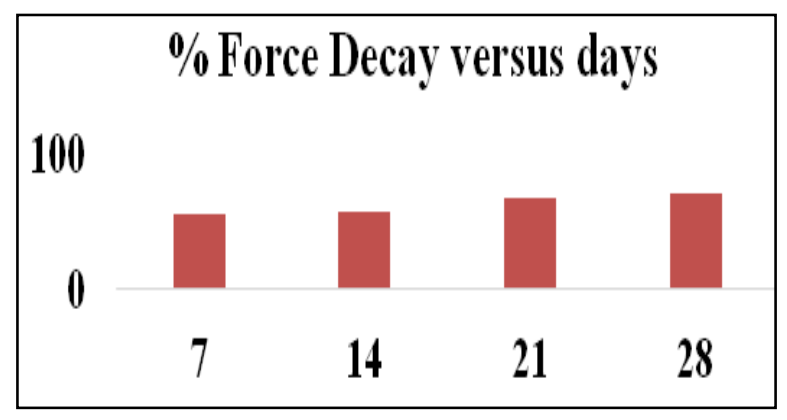

Fig 1. Percentage of force decay with respect to days

In the second descriptive statistics the comparison of force deterioration was done with the materials. It suggested that there was deterioration of the force in all the three materials.

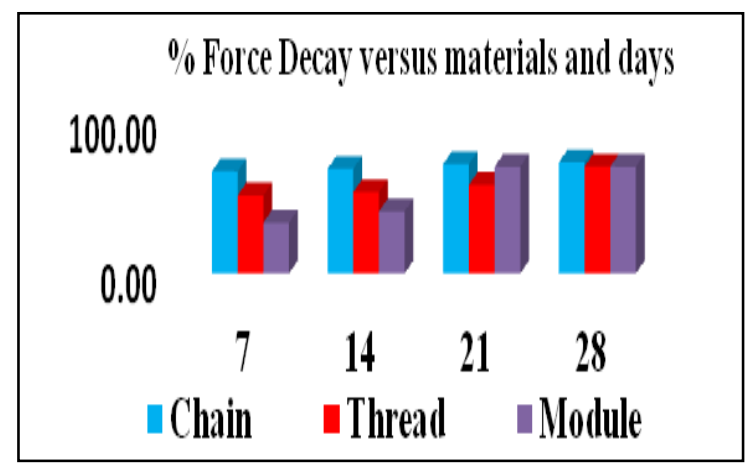

Fig 2. Percentage of force decay with respect to materials and days

The analysis showed that there was higher decay of the force on the $7^{\text {th }}$ day in all the three materials. In the elastomeric chains the decay of force was $67.71 \%, 69.43 \%$, $72.57 \%, 73.71 \%$ on the $7,14,21,28$ days respectively. In the elastomeric threads the decay of force was $51.76 \%, 53.99 \%, 58.79 \%, 70.93 \%$ on the $7,14,21,28$ days respectively. In the modules the force decay was $33.71 \%, 41.14 \%, 70.86 \%, 70.86 \%$ on the $7,14,21,28$ days respectively.

In the analysis of force decay with material it suggested that force decay in the chains was $56.69 \%$, in the threads it was $47.09 \%$, and in the modules it was $43.31 \%$. This suggested that the force decay in chains was more, then the decay of force was seen in threads and then in modules. 
In one-way (ANOVA) comparison between the force deterioration with time interval, there was more decay of force at the $7^{\text {th }}$ day, then there was less decay of force at the end of $14^{\text {th }}$ day, and then there was less force decay at end of $21^{\text {st }}$ and $28^{\text {th }}$ day which almost remained constant at the $21^{\text {st }}$ and $28^{\text {th }}$ day. Turkey's pair wise comparison was also done which suggested that there was difference in the force deterioration for the different interval period of time which was significant.

In all the three elastomeric materials initially there was higher force decay at the seventh day. Comparing all the three elastomeric materials, there was highest force decay seen in the chains, after that the force decay was seen in threads, and then in the modules. But there was a slight difference between threads and modules regarding the deterioration of the force. In which threads had slight more force deterioration compared to the modules. When the materials were evaluated individually comparing the factor time, the force was statistically higher in the initial period (day 0 ) than that of all the other experimental periods.

In general, the greater degradation of force occurred during the seventh day. From that on, the level of force continued to decrease, but slowly and gradually until the $21^{\text {st }}$ day and $28^{\text {th }}$ day.

\section{DISCUSSION}

The resiliency of elastic products has been exploited to form force delivery systems in orthodontics. However, as with all objects living and non-living, elastics do succumb to the laws of nature. Their force levels decrease with respect to the initial forces exerted. This property is known as the force decay [8]. The disadvantages of these materials are force decay or force relaxation due to permanent deformation of polymeric chains, water sorption, color changes and tooth surface decalcification due to bacterial accumulation $[9,10]$.

There have been a number of studies concerning dental elastomers and the degradation of strength with time, varying results have been reported. This inconsistency is the result of many different kinds of materials and experimental methods, making it difficult to compare the different products. Commonly, orthodontic consultations occur every 3 or 4 weeks, when the replacement of the elastomers happens. Thus, most studies evaluated the behavior of these materials for a period of 28 days [11].

In this experiment, products of the same brand i.e. (Ortho Organizers, USA) were used and their physical properties were examined with standardized environments. The study consisted total of 150 elastics. 50 samples were of chains, 50 samples were of thread, 50 samples were of module. All the samples were kept stretched at doubled its length in the artificial saliva, at different intervals of time. The results demonstrated that the highest level of force degradation occurred during the seventh day of the experiment.

Experiments carried out in dry and simulated oral environments of $100 \%$ humid conditions reported no significant differences for the different conditions. Greater force decay was observed in wet conditions than in dry conditions for the same temperature. So the present study was done in a simulated oral environment, using artificial saliva and incubated at $37 \pm 1^{0}$ Celsius [8].
The results obtained in this study showed that maximum force required to stretch was for chains, then for threads, and then it was for modules. Two-way ANOVA test suggested that the values obtained in all the three elastomers were highly significant. There was more deterioration of the force on the seventh day which gradually decreased on the $14^{\text {th }}$ day and remained almost constant on the $21^{\text {st }}$ and $28^{\text {th }}$ day. One-way ANOVA suggested that there was less force deterioration in the modules as compared to chains and threads. Turkey's pair wise comparison was also done which suggested that there was difference in the force deterioration for the different time interval which was significant.

The clinical implication of this finding is that, for modules with little variability, the amount of force produced by stretching an individual module at known distance could be recorded and used in subsequent similar clinical situations. For modules with high variability, however, every individual placement would require checking with a force gauge in order to quantify the force produced [12].

It would be reasonable for the manufacturers to expect clinicians to use their judgment in prescribing the use of particular elastics for their patients according to force requirements to be applied at specific intraoral elastic stretch distances. Nevertheless, the clinician has to rely on reasonable constancy of working properties for any elastic type; this requires quality control in manufacturing [3]. Clinical treatment procedures should be taken into consideration the rapid force decay of elastic materials that occur during the first day and the residual forces remaining[13].

Clinical use of elastics would ideally start with a measurement of the attachment points and selection of the elastic that would require stretching to three time's internal diameter to extend over that distance. It would be advisable to assess a sample of the elastics purchased to determine a range of forces because a product may not perform precisely as specified by the manufacturer. Clinically, the decision will have to be made about whether to start with a higher force than deemed necessary or end up with a lower force than desired after a very short time in the mouth [14].

Limitations: Although the findings from this study might be a useful guide to the anticipated clinical behavior of the elastomers tested, caution must always be exercised when extrapolating in vitro findings to the clinical environment. A logical extension of this study would be to test these elastomers in vivo. This would allow comparison of the force deterioration of these elastomers in an oral situation to determine whether the observed in vitro differences are clinically relevant.

\section{CONCLUSION}

Based on the results of this study, it can be concluded that: There was a force deterioration over time in all materials, being greatest on the seventh day of the experiment, especially more in the chains; From the third to the fourth week there was no noticeable force degradation in either group; By the end of the experiment, modules showed less deterioration of the force compared to the chains and threads.

Conflict of Interest: Declared none 


\section{REFERENCES}

1. Claire Nattrass, Anthony J Ireland, Martyn Sherrif. An Investigation into the placement of force delivery systems and the initial forces applied by clinicians during space closure. British Journal of Orthodontics.1997;24:127-31.

2. Sean Beattle, Peter Monaghan. An in vitro study simulating effects of daily diet and patient elastic band change compliance on orthodontic latex elastics. Angle Orthod 2004;74:234-9.

3. Kanchana P, Godfrey K. Calibration of force extension and force degradation characteristics of orthodontic latex elastics. Am J Orthod Dentofacial Orthop. 2000;118:280-7.

4. William A Brantley, Samuel Salander, C Louis Myers, Roberts V Winders. Effects of prestretching on force degradation characteristics of plastic modules. Angle Orthod1979;49:37-43.

5. Von Frounhofer JA, Coffelt MTP and Orbell GM. The effect of artificial saliva and topical fluoride treatments on the degradation of the elastic properties of orthodontic chains. Angle Orthod; 1992; 62 (4):265- 74

6. Teixeira L, Pereira Bdo R, Bortoly TG, Brancher JA, Tanaka OM, Guariza-Filho O. The environmental influence of Light Coke, phosphoric acid, and citric acid on elastomeric chains. J Contemp Dent Pract. 2008;9:17-24.

7. Claudia Kochenborger, Dayanne Lopes da Silva, Ernani Menezes Marchioro, Diogo Antunes Vargas, Luciane Hahn. Assessment of force decay in orthodontic elastomeric chains: An in-vitro study. Dental Press J Ortod 2011;16(6):93-9.

8. Shashanka P. Kumar, Dinesh MR, Amaranath BC, Dharma, Prashanth CS, Akshai Shetty KR. The evaluation and comparison of force degradation of latex and non latex intraoral elastics in a simulated oral environment: An in-vitro study. Orthodontic Cyber Journal.2010:1-23.

9. Eliades T, Eliades G, Watts DC. Structural conformation of in vitro and in vivo aged orthodontic elastomeric modules. European Journal of Orthodontics. 1999;21:649-58.

10. Eliades T, Eliades G, Watts DC. Tensile properties of orthodontic elastomeric chains. European Journal of Orthodontics 2004;26:157-62.

11. Andre Weeissheimer, Arno Locks, Luciane Macedo de Menezes, Adriano Ferreti Borgatto, Caria D' Agostini Derech. In vitro evaluation of force degradation of elastomeric chains used in orthodontics. Dental Press J Ortod 2013;18:55-62.

12. Garland Hershey and William G. Reynolds, Chapel Hill. The plastic module as an orthodontic toothmoving mechanism. Am. J Orthod . May 1975;67:554-62.

13. Allen K, Wong. Orthodontic Elastic Materials. Angle Orthodont 1976; 46:196-205.
14. Michael LK, Kenneth EG, Giseon Heo, Don Raboud, Paul W. Major A comparison of dynamic and static testing of latex and non-latex orthodontic elastics. Angle Orthodontist 2003;73:181-6. 